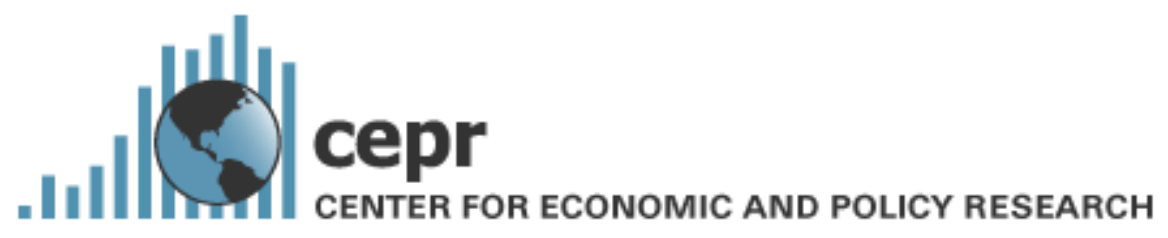

\title{
Are Shorter Work Hours Good for the Environment? A Comparison of U.S. and European Energy Consumption
}

\section{David Rosnick and Mark Weisbrot}

December 2006

Center for Economic and Policy Research 1611 Connecticut Avenue, NW, Suite 400

Washington, D.C. 20009

Tel: 202-293-5380

Fax:202-588-1356

www.cepr.net 


\section{Contents}

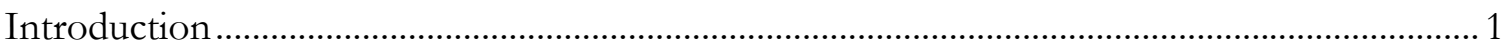

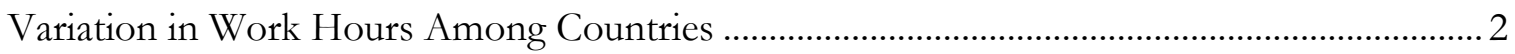

Variation in Energy Efficiency Among Countries ..................................................................... 4

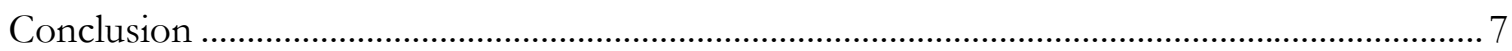

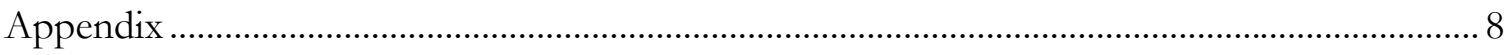

\section{About the Authors}

David Rosnick is a Research Associate and Mark Weisbrot is Co-Director at the Center for Economic and Policy Research in Washington, DC. 


\section{Introduction}

There is an important political debate in Europe over whether Europeans would be better off economically if they moved toward a U.S.-style economic model, most importantly in their labor markets. The conventional wisdom, in both academic circles and the media, is that they would, and there is transatlantic consensus that Europe needs more labor market flexibility, including increased latitude of employers to fire employees, less regulation of business, lower payroll taxes, reduced public pensions, unemployment compensation and other payments, lower wages and benefits attached to employment, and a reduced influence of unions. Yet, the empirical evidence for this view has been weak. ${ }^{1}$

But aside from the economic and political implications, there are potentially large costs to the environment if European countries were to move to a U.S.-style economic model. Europe currently consumes about half as much energy per person as the United States, and this would change if Europeans worked as many hours as U.S. workers do.

This paper looks at the potential environmental effects of such a change. If the countries of "Old Europe" ${ }^{\prime 2}$ were to adopt U.S. practices and increase annual work hours ${ }^{3}$ to American levels, they could consume some 30 percent more energy than they do at present. Not only could that impact fuel prices worldwide, but the resulting carbon emissions would make it far more difficult for the EU to meet its commitments to the Kyoto Protocol.

As the economies of developing countries grow, those nations will look to the U.S. and European labor models. Worldwide energy patterns, therefore, will be dependent on which model developing countries choose in the next few decades. If, by $2050^{4}$, the world works as many hours as do Americans it could consume 15-30 percent more energy than it would following Europe. The additional carbon emissions could result in 1 to 2 degrees Celsius in extra global warming.

Although it is not high on the political agenda at this time, there is the possibility of the reverse outcome: that the United States moves more in the direction of Europe, which would reduce energy consumption. For example, if the United States had adopted European standards for work hours, U.S. carbon dioxide emissions in 2000 would have been 7 percent lower than its actual 1990 emissions - the negotiated goal for the U.S. in meeting Kyoto. This paper will look at these relationships between work hours and energy consumption.

1 See David Howell, Dean Baker, Andrew Glyn and John Schmitt, 2006. “Are Protective Labor Market Institutions Really at the Root of Unemployment? A Critical Perspective on the Statistical Evidence.” Washington, DC: CEPR.

[http://www.cepr.net/documents/2006_07_unemployment_institutions.pdf]

The idea that reforms moving toward the U.S. model would reduce social exclusion in Europe has also been challenged see Schmitt, John and Ben Zipperer, 2006. "Is the U.S. a Good Model for Reducing Social Exclusion in Europe?”

Washington, D.C.: CEPR. [http://www.cepr.net/documents/social exclusion 2006 08.pdf]

2 The EU-15 are: Austria, Belgium, Denmark, Finland, France, Germany, Greece, Ireland, Italy, Luxembourg, the Netherlands, Portugal, Spain, Sweden, and the United Kingdom.

3 This paper does not take into account any differences in employment rates between the United States and Europe. However, it is worth noting that employment rates for prime age workers (ages 25 to 54) in Europe are currently only slightly lower than in the United States.

4 The adoption by the EU-15 of a U.S.-style work and consumption pattern would increase total EU and U.S. energy consumption by 7 to 16 percent; and a switch by the United States to European work and consumption patterns would lower total EU and U.S. energy consumption by 8 to 14 percent. Thus, there is a difference of 15 to 30 percent in energy consumption between the two scenarios. Applying these estimates to the entire world, including developing countries, leads to a difference of 1 to 2 degrees Celsius in global climate change. 


\section{Variation in Work Hours Among Countries}

It is well known that Europe lags behind the United States in terms of GDP per capita. However, it is less well known that European workers in a number of countries are nearly as productive, and in some cases more productive, than their American counterparts. As seen in Table 1, GDP per hour worked in Germany (including the former East Germany) was $\$ 30.73$ compared to $\$ 33.77$ in the United States. France was even more productive than the United States, with a GDP per hour worked of \$37.01.

TABLE 1

Productivity and GDP per Capita

\begin{tabular}{rlrc}
\hline \hline Rank & Country/Region & $\begin{array}{c}\text { GDP per Civilian Work Hour in } \\
\mathbf{2 0 0 3} \text { (1995 PPP dollars) }\end{array}$ & $\begin{array}{c}\text { GDP per Capita in 2003 } \\
\text { (1995 PPP dollars) }\end{array}$ \\
\hline & & & \\
1 & Norway & $\$ 38.61$ & $\$ 26,035$ \\
2 & France & 37.01 & 21,861 \\
3 & Luxembourg & 36.36 & 35,282 \\
$\mathbf{4}$ & United States & $\mathbf{3 3 . 7 7}$ & $\mathbf{2 9 , 0 3 7}$ \\
5 & Ireland & 33.17 & 24,720 \\
6 & Belgium & 32.70 & 21,236 \\
7 & Netherlands & 31.15 & 21,472 \\
8 & Austria & 30.76 & 21,198 \\
9 & Germany & 30.73 & 19,143 \\
10 & Denmark & 29.80 & 23,133 \\
11 & Sweden & 28.93 & 21,640 \\
& "Old Europe" (EU-15) Average & $\mathbf{2 8 . 8 9}$ & $\mathbf{1 9 , 8 1 3}$ \\
12 & Italy & 28.43 & 19,151 \\
13 & United Kingdom & 28.08 & 21,310 \\
14 & Finland & 27.68 & 20,509 \\
15 & Australia & 27.60 & 23,287 \\
16 & Canada & 27.24 & 23,236 \\
& Non-U.S. Average & $\mathbf{2 6 . 0 8}$ & $\mathbf{1 9 , 0 4 3}$ \\
17 & Switzerland & 25.68 & 22,189 \\
18 & Japan & 24.28 & 21,218 \\
19 & Spain & 22.12 & 17,021 \\
20 & Iceland & 21.99 & 21,507 \\
21 & New Zealand & 20.31 & 17,565 \\
22 & Greece & 17.57 & 13,631 \\
23 & Portugal & 16.97 & 14,100 \\
24 & Turkey & 11.24 & 6,731 \\
& & & \\
\hline & G & & \\
Sing & & \\
\end{tabular}

Source: Groningen Growth and Development Data Centre and the Conference Board, Total Economy Database

So why do other advanced countries lag behind the United States in GDP per capita? They simply work fewer hours. In small part, this is due to EU-15 countries having lower employment-to-population rates than in the United States (approximately 64.4 percent of all people aged 15 to 64 compared to 71.2 percent in the United States.) In large measure, however, the reduced hours are conditional on employment. Employed Americans work 16 percent more hours than their EU-15 counterparts.

Mandatory paid vacations and shorter workweeks mean that workers in other countries have gotten some of their productivity advances in the form of reduced hours. Workers in the United States work more hours of every year than do workers in almost every other developed country. In general, the higher the GDP per hour worked, the fewer the average work hours. Table 2 shows the average annual 
hours worked per person employed for various countries in 2001. That year, American workers spent an average of 1,817 hours on the job, compared to an average of 1,650 hours in all the other countries listed. Workers in the EU-15 worked even fewer hours at only 1,562-some 14 percent less time on the job compared to those in the United States. Assuming an average of 35 hours per week, this difference corresponds to more than seven weeks of additional time off (in both leave and shorter workweeks) per worker each year.

TABLE 2

Work Hours

\begin{tabular}{rlcc}
\hline Rank & Country/Region & $\begin{array}{c}\text { Average Hours Worked per } \\
\text { Civilian Employee in 2003 }\end{array}$ & $\begin{array}{c}\text { Rank in GDP per } \\
\text { Work Hour }\end{array}$ \\
\hline & Norway & 1336 & 1 \\
2 & Netherlands & 1352 & 7 \\
3 & France & 1429 & 2 \\
4 & Germany & 1441 & 8 \\
5 & Austria & 1497 & 3 \\
6 & Luxembourg & 1513 & 10 \\
7 & Denmark & 1519 & 17 \\
8 & Switzerland & 1537 & 11 \\
9 & Sweden & 1553 & 12 \\
& “Old Europe” (EU-15) Average & $\mathbf{1 5 6 2}$ & 6 \\
10 & Italy & 1609 & 13 \\
11 & Belgium & 1619 & 14 \\
12 & United Kingdom & 1624 & 5 \\
13 & Finland & 1634 & 23 \\
& Non-U.S. Average & $\mathbf{1 6 5 0}$ & 21 \\
14 & Ireland & 1653 & 15 \\
15 & Portugal & 1702 & 18 \\
16 & New Zealand & 1752 & 16 \\
17 & Australia & 1756 & 19 \\
18 & Japan & 1760 & 20 \\
19 & Canada & 1764 & $\mathbf{4}$ \\
20 & Spain & 1799 & 22 \\
21 & Iceland & 1807 & 24 \\
$\mathbf{2 2}$ & United States & $\mathbf{1 8 1 7}$ & \\
$23(\mathrm{t})$ & Greece & 1929 & 16 \\
$23(\mathrm{t})$ & Turkey & 1929 & \\
& & & \\
\hline
\end{tabular}

Source: Groningen Growth and Development Data Centre and the Conference Board, Total Economy Database ( $\mathrm{t}$ indicates tied rank)

As can been seen in Table 2, not only do U.S. employees work more hours than in almost all other highincome countries, but they work an unusually high number of hours for the country's level of productivity. In other words, the only countries that come close to or exceed the United States' annual hours worked tend to have lower productivity. 


\section{Variation in Energy Efficiency Among Countries}

As can be seen in Figure 1, the least energy efficient countries - as measured by energy consumed per dollar of GDP - are generally those in colder climates.

\section{FIGURE 1}

Energy Consumed per Dollar of GDP

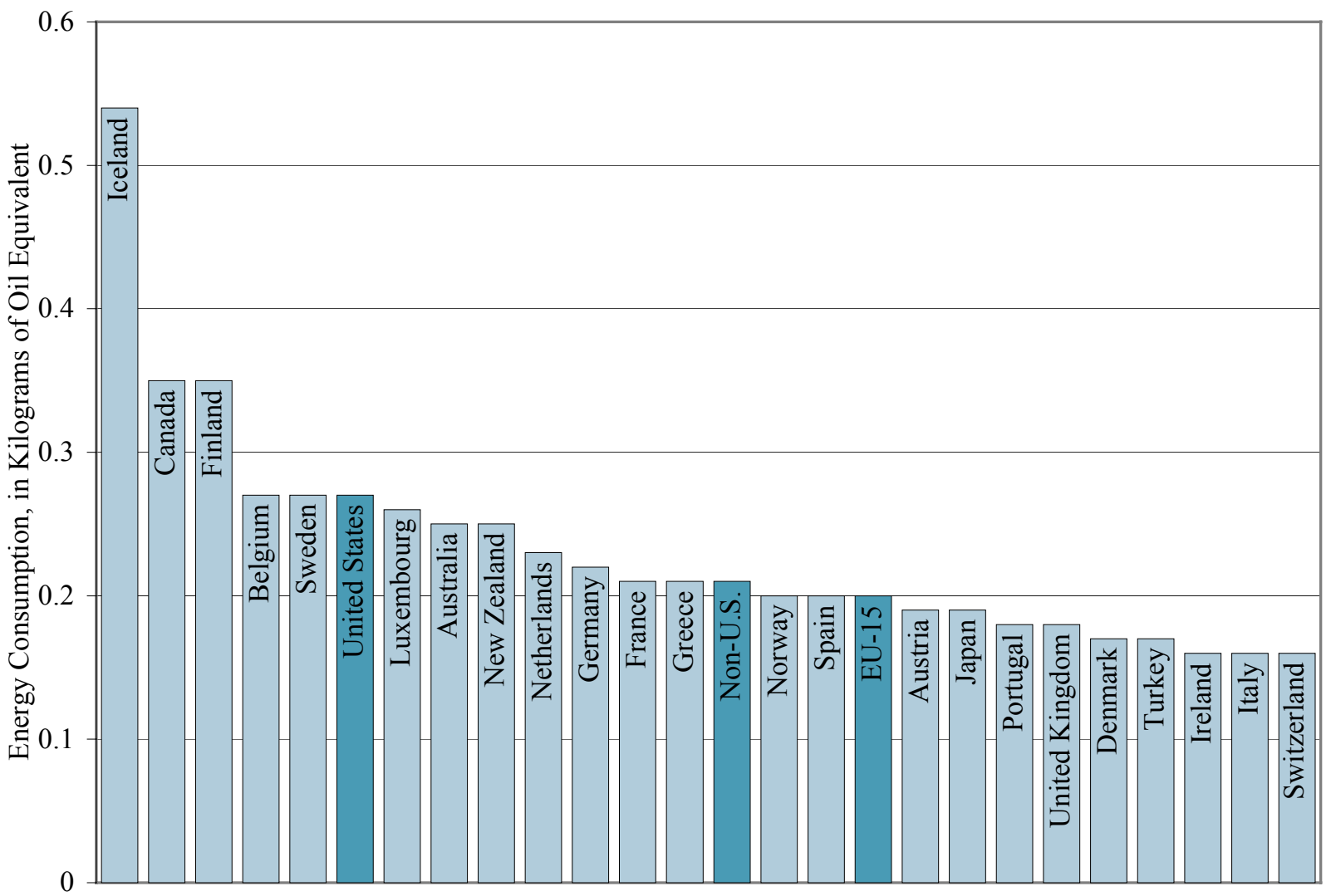

Source: Groningen Growth and Development Data Centre and the Conference Board, Total Economy Database and World Bank, World Development Indicators 2005.

Ireland, Italy, and Switzerland appear to be energy efficient, while Iceland, Canada, and Finland, are energy inefficient. ${ }^{5}$

\section{Longer Work Hours Means More Energy Use}

Countries where people work fewer hours use much less energy than the United States. If we assume constant energy efficiency (energy per unit of GDP) and a constant productivity (GDP per hour of work), then energy use per hour of work must be constant. Table 4 shows that, under this simplifying

\footnotetext{
${ }^{5}$ Clearly, the fact that Canada, Iceland, and Finland have land within the Arctic Circle is a contributing factor. Ideally, the climate of the country should be controlled for in this comparison.
} 
assumption, if workers in "Old Europe" had worked as many hours in 2003 as had workers in the United States, the EU-15 would have consumed 18 percent more energy. ${ }^{6}$

TABLE 3

Scenario 1-Constant Energy per Work Hour

\begin{tabular}{|c|c|c|}
\hline & \multicolumn{2}{|c|}{ Change in Energy Consumption } \\
\hline & Region & 16 or 24 Country Total ${ }^{7}$ \\
\hline 23 Developed Countries at U.S. Work Hours & $12 \%$ & $7 \%$ \\
\hline EU-15 at U.S. Work Hours & 18 & 7 \\
\hline U.S. at 23 Developed Country Work Hours & -9 & -3 \\
\hline U.S. at EU-15 Work Hours & -14 & -8 \\
\hline
\end{tabular}

Table 3 represents a simplified estimation of how energy consumption per country would increase if work hours increased. However, the relationship between energy consumption and work hours could be more complicated. For example, workers (or families) with less leisure time may dry their laundry by machine rather than drying it on a clothesline. They may not take the time to walk or bicycle to work, but rather drive. These behavioral changes in response to increased work hours would cause energy efficiency to decline as work hours increased. On the other hand, they may have their clothes professionally laundered, or take a cab. While these decisions would increase energy consumption, they would also increase hours worked in the economy, so the effect on this measure of energy efficiency is indeterminate. Finally, they may pay professionals to paint their homes rather than do it themselves. While this would consume the same amount of much energy, it would increase hours worked, thereby increasing this measure of energy efficiency. Of course, as people leave their homes to work, energy savings at home might balance the extra energy consumed at work. Any net effect of work hours on energy consumption is not easy to predict.

We therefore try to estimate this relationship between energy efficiency (as measured per hours worked) and an increase in hours. The appendix explains how this is done. Based on this estimation, we can delineate a range of possible relationships between an increase in work hours and energy consumed.

Table 4 takes the low estimate of this range: that every one percent increase in work hours per worker results in a 0.32 percent increase in energy consumed per work hour. In other words, energy use per work hour increases as work hours increase, but here we are using the lowest (most conservative) estimate of the amount by which it increases. ${ }^{8}$

\footnotetext{
${ }^{6}$ Energy data is taken from the World Bank, World Development Indicators 2005. Each country's energy consumption is scaled up proportionate to an increase in average hours that would bring them to the U.S. level of hours. For example, U.S. workers worked 27 percent more hours than those in France, so in this scenario France is assumed to consume 27 percent more energy if it increased work hours to the U.S. level. Summing these levels of energy usage for all the EU-15, the total is 18 percent greater than the actual total energy consumption of the EU-15 in 2003.

7 See Appendix, Table A1 for country groupings.

8 See Appendix for details.
} 
TABLE 4

Scenario 2-Increasing Work Hours Leads to Moderate Decrease in Energy Efficiency

Change in Energy Consumption

Region

16 or 24 Country Total

23 Developed Countries at U.S. Work Hours

EU-15 at U.S. Work Hours

$17 \%$

25

U.S. at 23 Developed Country Work Hours

$-12$

$9 \%$

U.S. at EU-15 Work Hours

$-18$

10

$-4$

$-10$

TABLE 5

Scenario 3-Increasing Work Hours Leads to Large Decrease in Energy Efficiency

\begin{tabular}{|c|c|c|}
\hline & \multicolumn{2}{|c|}{ Change in Energy Consumption } \\
\hline & Region & 16 or 24 Country Total \\
\hline 23 Developed Countries at U.S. Work Hours & $27 \%$ & $14 \%$ \\
\hline EU-15 at U.S. Work Hours & 41 & 16 \\
\hline U.S. at 23 Developed Country Work Hours & -18 & -6 \\
\hline U.S. at EU-15 Work Hours & -26 & -14 \\
\hline
\end{tabular}

Collectively, these three scenarios cover a range of possible energy responses to changes in work hours. If, in 2003, other developed country workers worked as many hours as Americans, by these estimates they would have consumed anywhere from 12 to 41 percent more energy. Similarly, if Americans traded work for leisure, they could reduce their energy needs by 9 to 26 percent. 


\section{Conclusion}

If Americans chose to take advantage of their high level of productivity by shortening the workweek or taking longer vacations rather than producing more, there would follow a number of benefits. Specifically, if the U.S. followed the EU-15 in terms of work hours, then:

- Employed workers would find themselves with seven additional weeks of time off.

- The United States would consume some 20 percent less energy.

- If a 20 percent energy savings had been directly translated into lower carbon emissions, then the U.S. would have emitted 3 percent less carbon dioxide in 2002 than it did in 1990. ${ }^{9}$ This level of emissions is only 4 percent above the negotiated target of the Kyoto Protocol.

On the flip side, there is political pressure within European countries to adopt a more American labor model. If Europeans did in fact give up their shorter workweeks and longer vacations, they would consume some additional 25 percent more energy. Translated into carbon emissions, this would have enormous consequences for those countries that have signed and ratified the Kyoto Protocol. Over 1990 levels, ${ }^{10}$ the EU-15 emitted 8 percent more carbon dioxide in 2002, despite a clear commitment to reduce emissions to 8 percent below 1990 levels by 2008-12. Thus, the EU-15 must cut emissions by 14 percent from 2002 levels. However, if EU-15 workers had consumed 25 percent more energy and consequently emitted 25 percent more carbon dioxide in 2002, they would have had to cut emissions by more than one-third from that level to meet their commitment to Kyoto.

According to the IPCC Third Assessment Report, ${ }^{11}$ the amount of global warming is tied to the speed by which emissions are cut. If by 2050 the world is emitting 10Gt (10 billion metric tons) of carbon, we may be on a path to 2.5 degrees Celsius of warming. On the other hand, if the level of emissions is $14 \mathrm{Gt}$ of carbon dioxide in 2050 may mean 4.5 degrees of warming. A worldwide choice of American work hours over European levels could result in 1 to 2 degrees Celsius of additional warming, in addition to higher fuel prices.

Finally, the debate over the European and American models, depending on the extent to which either side prevails, will have economic and environmental implications for a number of middle-income countries. These countries - especially the fast-growing economies of Asia - will most likely choose between these two models of labor market institutions and consumption. South Korea and Taiwan are already at European levels of GDP per capita. China (at $\$ 8,004$ per person) is still far behind but is growing rapidly and is the second largest economy in the world in absolute size, ${ }^{12}$ and at current growth rates will pass the United States in less than a decade. The American model is still portrayed throughout the international business press as the one to emulate. The environmental consequences of developing countries' choices could be very serious.

\footnotetext{
9 Carbon dioxide emission data is from the World Bank, World Development Indicators 2005.

10 Missing data is imputed for Germany in 1990.

11 See, for example, page 20 of the Synthesis Report, Climate Change 2001.

12 This is based on a purchasing power parity measure of GDP (IMF WEO September 2006).
} 


\section{Appendix}

Energy consumption is almost certainly a function of a country's level of development. It may also be a function of average hours worked per employee. That is,

$$
\frac{E}{P}=f\left(\frac{Y}{H}, \frac{H}{W} ; \frac{W}{P}\right)
$$

where $\mathrm{E}$ is energy consumed in $\mathrm{kg}$ of oil equivalent, $\mathrm{H}$ is total hours worked in the country, $\mathrm{Y}$ is GDP, and $\mathrm{W}$ is the number of employed workers in a country of population $\mathrm{P} .{ }^{13}$ We may start with the more general model

$$
E=g(Y, H, W ; P)
$$

Suppose g takes the form

$$
g(Y, H, W ; P)=\alpha Y^{\beta} H^{\gamma} W^{\delta} P^{\varepsilon}
$$

It is easy to imagine that if the population of a country doubled, that the number of workers would double, and likely the number of total hours worked and GDP of the country would double. If all these doubled, we might also expect energy consumption for the country to double. This "constant returns to scale" means

which implies

$$
k E=k g=\alpha(k Y)^{\beta}(k H)^{\gamma}(k W)^{\delta}(k P)^{\varepsilon}=k^{\beta+\gamma+\delta+\varepsilon} g
$$

$$
\beta+\gamma+\delta+\varepsilon=1
$$

Instead of directly imposing this restriction, we can write

$$
\beta+\gamma+\delta+\varepsilon=1+\theta
$$

Substituting back in to the equation for $g$, we find

$$
g(Y, H, W ; P)=\alpha Y^{\beta} H^{\gamma} W^{\delta} P^{1+\theta-\beta-\gamma-\delta}=\alpha\left(\frac{Y}{H}\right)^{\beta}\left(\frac{H}{W}\right)^{\beta+\gamma}\left(\frac{W}{P}\right)^{\beta+\gamma+\delta} P^{1+\theta}
$$

In other words, this form of g gives one plausible model for $f$,

$$
f\left(\frac{Y}{H}, \frac{H}{W} ; \frac{W}{P}\right)=\frac{E}{P}=\frac{g(Y, H, W ; P)}{P}=\alpha\left(\frac{Y}{H}\right)^{\beta}\left(\frac{H}{W}\right)^{\beta+\gamma}\left(\frac{W}{P}\right)^{\beta+\gamma+\delta} P^{\theta}
$$

which produces constant returns to scale when $\theta=0$.

\footnotetext{
${ }^{13}$ In part, we are interested in per-capita energy consumption on account of the differing population series in the World Bank and Groningen data sets.
} 
We also wish to control in some way for temperature, recognizing that climate can be expected to impact energy consumption-countries near the Arctic likely consume much more energy to stay warm. As a proxy for countrywide climate, we include a control for the average year-round temperature of the capital. ${ }^{14}$ There are 48 countries for which we have 2003 data. We also consider the smaller set of 24 countries that make up the primary grouping in the Groningen data, and then the 16 countries that make up the EU-15 plus the United States. The 48 countries, plus membership in the groups of 24 and 16 are listed in Table A1.

TABLE A1

Country Groups

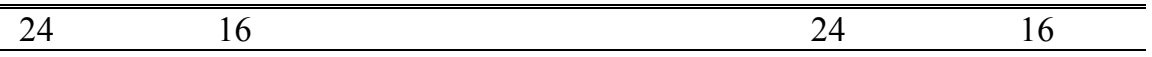

\begin{tabular}{|c|c|c|c|c|c|}
\hline \multicolumn{3}{|l|}{ Argentina } & \multicolumn{3}{|l|}{ Latvia } \\
\hline Australia & $*$ & & Lithuania & & \\
\hline Austria & * & * & Luxembourg & * & $*$ \\
\hline Bangladesh & & & Malaysia & & \\
\hline Belgium & * & * & Malta & & \\
\hline Brazil & & & Mexico & & \\
\hline Canada & * & & Netherlands & $*$ & * \\
\hline Chile & & & New Zealand & * & \\
\hline Columbia & & & Norway & $*$ & \\
\hline Cyprus & & & Pakistan & & \\
\hline Czech Republic & & & Poland & & \\
\hline Denmark & * & * & Portugal & $*$ & * \\
\hline Estonia & & & Singapore & & \\
\hline Finland & * & * & Slovak Republic & & \\
\hline France & * & * & Slovenia & & \\
\hline Germany & $*$ & * & Spain & $*$ & * \\
\hline Greece & * & * & Sri Lanka & & \\
\hline Hong Kong & & & Sweden & $*$ & * \\
\hline Hungary & & & Switzerland & $*$ & \\
\hline Iceland & $*$ & & Thailand & & \\
\hline Ireland & * & * & Turkey & * & \\
\hline Italy & * & * & United Kingdom & * & * \\
\hline Japan & * & & United States & $*$ & * \\
\hline Korea & & & Venezuela & & \\
\hline
\end{tabular}

For each group of countries, we regress to find the coefficients of $f$. Checking to see if the coefficients suggest constant returns to scale, we examine the coefficient on P. Last, we regress on the reduced form of $f$, assuming theta to be zero. The results are presented in Table A2.

${ }^{14}$ Data from http://www.weatherbase.com 
TABLE A2

Regression Results-Dependent variable: $\log ($ energy consumed per capita)

\begin{tabular}{lllllll}
\hline country set & \multicolumn{2}{c}{48} & \multicolumn{2}{c}{24} & \multicolumn{2}{c}{16} \\
\hline & & & & & & \\
constant & -2.85 & -2.77 & $-14.7^{* * *}$ & $-14.7^{* * *}$ & -7.72 & -7.51 \\
& $(0.774)$ & $(0.819)$ & $(2.91)$ & $(3.00)$ & $(1.22)$ & $(1.22)$ \\
$\log (\mathrm{GDP} /$ hour $)$ & $0.953^{* * *}$ & $0.952^{* * *}$ & $1.33^{* * *}$ & $1.33^{* * *}$ & $1.13^{* * *}$ & $1.19^{* * *}$ \\
& $(8.28)$ & $(8.42)$ & $(5.49)$ & $(5.94)$ & $(3.38)$ & $(3.80)$ \\
$\log$ (hours/worker) & $1.33^{* * *}$ & $1.32^{* * *}$ & $2.83^{* * *}$ & $2.84^{* * *}$ & $1.89^{* *}$ & $1.86^{* *}$ \\
& $(3.01)$ & $(3.17)$ & $(4.62)$ & $(4.76)$ & $(2.37)$ & $(2.41)$ \\
$\log$ & $1.22^{* * *}$ & $1.22^{* * *}$ & $1.36^{* * *}$ & $1.34^{* * *}$ & $1.27^{*}$ & $1.06^{*}$ \\
(workers/population) & $(3.30)$ & $(3.44)$ & $(3.13)$ & $(3.78)$ & $(2.07)$ & $(2.07)$ \\
$\log$ (population) & 0.0020 & & 0.0036 & & 0.033 & \\
& $(0.061)$ & & $(0.092)$ & & $(0.67)$ & \\
$\log ($ temperature) & $-0.351^{* * *}$ & $-0.348^{* * *}$ & $-0.549^{* * *}$ & $-0.542^{* * *}$ & $-0.491^{*}$ & $-0.429^{*}$ \\
& $(3.06)$ & $(3.36)$ & $(3.75)$ & $(4.45)$ & $(2.21)$ & $(2.18)$ \\
$\mathrm{R}^{\wedge} 2$ & 0.876 & 0.876 & 0.854 & 0.854 & 0.779 & 0.769 \\
F - model & $59.6^{* * *}$ & $76.2^{* * *}$ & $21.1^{* * *}$ & $27.9^{* * *}$ & $7.05^{* * *}$ & $9.17^{* * *}$ \\
& & & & & & \\
\hline \hline
\end{tabular}

* Significant at $10 \%$

** Significant at $5 \%$

$* * *$ Significant at $1 \%$

As can be seen in Table A2, the regressions do suggest constant returns to scale in that the coefficient on population is indistinguishable from zero and the remaining coefficients change very little in shifting to the reduced equation. The coefficient on hours per worker, though highly significant, is in most cases not significantly different from 1.0. This means these regressions do not consistently show a gain in energy efficiency on account of reduced work hours. Specifically, the regressions on the groups of 48 and 16 are consistent with the assumptions of Scenario 1. However, there is a wide range of estimates of the coefficient of interest. For that reason, we are inclined to be conservative in our central estimate and assume a 0.32 percent increase in energy consumed per work hour for a 1 percent increase in hours per worker. (A 1.32 percent increase in energy consumed per capita for a 1 percent increase in hours per worker.) For our high estimate, we will continue to be conservative and assume a 1 percent increase in energy consumed per work hour for a 1 percent increase in hours per worker. ${ }^{15}$

\footnotetext{
15 The regression results indicate that we can say with 90 percent confidence that the actual effect in the group of 24 is larger than our high estimate.
} 